\title{
Erratum to: The Clinical Utility of TIMP3 Expression in ACTH-Secreting Pituitary Tumor
}

\author{
Bowen Sun ${ }^{1}$ - Xiaohai Liu ${ }^{1}$ - Yakun Yang ${ }^{1}$ Congxin Dai ${ }^{1} \cdot{\text { Ying } \mathrm{Li}^{2}}^{2}$ Yonghui Jiao ${ }^{1}$. \\ Zhenqing $\mathrm{Wei}^{1} \cdot$ Yong Yao $^{1} \cdot \mathrm{Ming} \mathrm{Feng}^{1} \cdot \mathrm{Xinjie} \mathrm{Bao}^{1} \cdot \mathrm{Kan}^{\mathrm{Deng}}{ }^{1} \cdot \mathrm{Ning} \mathrm{Wang}^{2}$ • \\ Renzhi Wang ${ }^{1}$
}

Published online: 19 February 2016

(C) Springer Science+Business Media New York 2016

Erratum to: J Mol Neurosci (2016) 58:137-144

DOI: $10.1007 / \mathrm{s} 12031-015-0698-z$

The original version of this article unfortunately contained mistakes in Figs. 3 and 4. The correct versions are presented below:

a

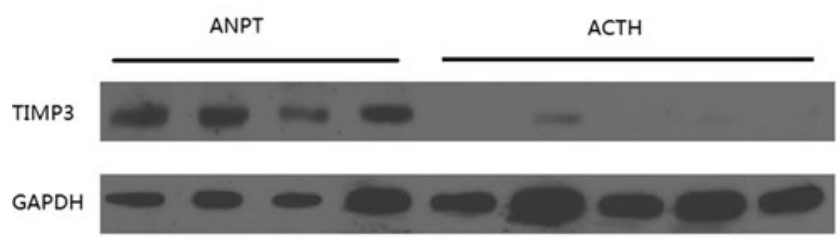

Fig. 3 a TIMP3 protein levels in ACTH-secreting pituitary adenomas and adjacent non-tumorous pituitary tissues assessed by Western blotting. Graph shows the TIMP3 GAPDH relative ratio in 10 tumors samples and

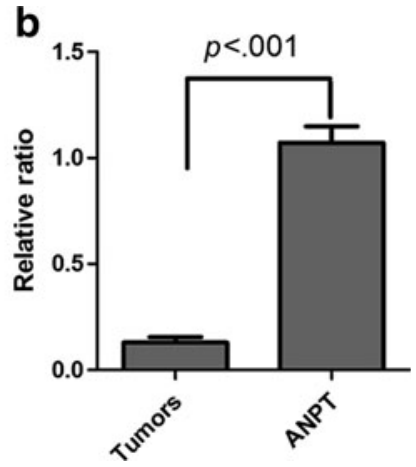

10 ANPT. $p<0.001$. b Panel representative western blots of 5 tumors and 4 ANPT samples. ACTH adrenocorticotropic hormone, ANPT nontumorous pituitary tissue

The online version of the original article can be found at http://dx.doi.org/ 10.1007/s12031-015-0698-z.

Renzhi Wang

wrzpumch@163.com

1 Department of Neurosurgery, Peking Union Medical College Hospital, Chinese Academy of Medical Sciences, Peking Union Medical College, Beijing 100730, China

2 Department of Neurosurgery, the First Affiliated Hospital, Harbin Medical University, Harbin 150001, China 

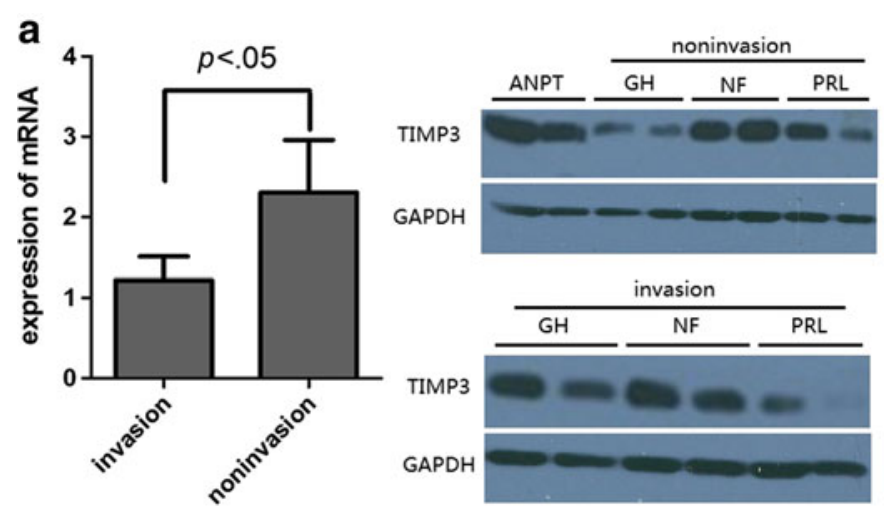

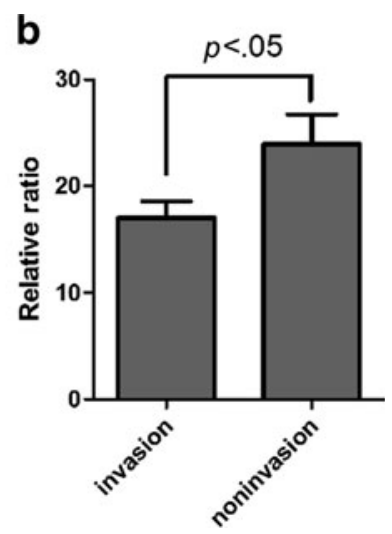

Fig. 4 a TIMP3 mRNA expression in invasive and noninvasive PAs. TIMP3 mRNA levels were significantly higher in the noninvasive PAs than in the invasive PAs $(p<.05)$. b TIMP3 protein levels in different subtype pituitary adenomas and adjacent non-tumorous pituitary tissues assessed by Western blotting, and compared invasive PAs with noninvasive PAs. TIMP3 tissue inhibitor of metalloproteinase $3, N F$ nonfunctional adenoma, $P R L$ prolactin, $G H$ growth hormone, $A N P T$ non-tumorous pituitary tissue 